\title{
INJEÇÃO DE NITROGÊNIO WASTE NÃO UTILIZADO EM NITROGÊNIO DE BAIXA PRESSÃO*
}

\author{
Igor Martins dos Santos ${ }^{1}$ \\ Marcus Vinicius da Fonseca Buarque ${ }^{2}$ \\ Rafael Cesar de Souza ${ }^{3}$ \\ Ricardo Santos de Oliveira ${ }^{4}$ \\ Vilson Jose da Anunciação ${ }^{5}$ \\ Fabio Ricardo Zuege ${ }^{6}$
}

\section{Resumo}

O nitrogênio waste, que é chamado assim por ser mais impuro, devido à existência de uma porcentagem aproximada de $2 \%$ mais de oxigênio no mesmo, utilizado exclusivamente no processo de "Slag Splash" na Aciaria, possui um contrato fechado de volume para fornecimento $\left(7.000 \mathrm{Nm}^{3} / \mathrm{h}\right.$, à pressão de 30 bar), o qual estava sendo utilizada aproximadamente a metade do mesmo $\left(3.500 \mathrm{Nm}^{3} / \mathrm{h}\right)$. Como no processo produtivo da CSA, é utilizado o nitrogênio de baixa pressão (16 bar) em grande quantidade $\left(21.600 \mathrm{Nm}^{3} / \mathrm{h}\right.$, sendo aproximadamente $5.600 \mathrm{Nm}^{3} / \mathrm{h}$ acima do contrato de fornecimento), foi feito um projeto para interligar as duas linhas de nitrogênio através de aproximadamente 420 metros de tubulação, com sistema de controle integrado e analisador de oxigênio para garantir a concentração mínima de $1 \%$ de oxigênio no Nitrogênio de baixa pressão, devido à necessidade de algumas áreas. Nos primeiros seis meses após implantação, foi contabilizado uma economia de aproximadamente $R \$ 4.0$ milhões (aproximadamente $3.100 \mathrm{Nm}^{3} / \mathrm{h}$ de consumo).

Palavras-chave:Nitrogênio; Redução; Custo.

\section{WASTE NITROGEN INJECTION NOT USED IN LOW PRESSURE NITROGEN Abstract}

The waste nitrogen, which is so called because it is impure, due to the existence of an approximate percentage of $2 \%$ more oxygen in it, used exclusively in the "Slag Splash" process in the Steelworks, has a closed volume contract for supply $(7,000$ $\mathrm{Nm}^{3} / \mathrm{h}$ at a pressure of $\left.30 \mathrm{bar}\right)$, which was being used approximately half of it $(3,500$ $\mathrm{Nm}^{3} / \mathrm{h}$ ). As in the CSA production process, low pressure nitrogen (16 bar) is used in a large quantity $\left(21,600 \mathrm{Nm}^{3} / \mathrm{h}\right.$, being approximately $5,600 \mathrm{Nm}^{3} / \mathrm{h}$ above the supply contract), a project was done to interconnect the two lines of Nitrogen through approximately 420 meters of piping, with integrated control system and oxygen analyzer to ensure the minimum concentration of $1 \%$ oxygen in the Nitrogen low pressure due to the need for some areas. In the first six months after implementation, an economy of approximately $R \$ 4.0$ million (approximately $3,100 \mathrm{Nm}^{3} / \mathrm{h}$ of consumption) was accounted for.

Keywords: Nitrogen; Reduction; Cost.

1 Engenheiro Mecânico, Engenheiro de Manutenção Mecânica, Gerência de Distribuição de Energia e Utilidades, Companhia Siderúrgica do Atlântico, Santa Cruz, Rio de Janeiro, Brasil.

2 Engenheiro Civil, Coordenador de Manutenção, Gerência de Distribuição de Energia e Utilidades, Companhia Siderúrgica do Atlântico, Santa Cruz, Rio de Janeiro, Brasil.

3 Técnico de Eletrônica, Coordenador de Otimização de Processos, Gerência de Distribuição de Energia e Utilidades, Companhia Siderúrgica do Atlântico, Santa Cruz, Rio de Janeiro, Brasil

4 Engenheiro Mecânico, Técnico Especialista, Gerência de Distribuição de Energia e Utilidades, Companhia Siderúrgica do Atlântico, Santa Cruz, Rio de Janeiro, Brasil

5 Administrador, Analista de Desenvolvimento, Gerência de Distribuição de Energia e Utilidades, Companhia Siderúrgica do Atlântico, Santa Cruz, Rio de Janeiro, Brasil

6 Engenheiro Elétrico, Engenheiro Especialista em Sistemas Utilidades, Gerência de Distribuição de Energia e Utilidades, Companhia Siderúrgica do Atlântico, Santa Cruz, Rio de Janeiro, Brasil. 


\section{INTRODUÇÃO}

Em indústrias siderúrgicas de grande porte, temos uma grande variedade de gases aplicados nos mais diversos processos, dentre eles gases criogênicos e gases industriais (ou gases de processo). Com o passar do tempo e estabilização dos processos, começam a surgir oportunidades de melhorias nos processos, como:

- Otimização do uso de recursos

- Otimização da rotina

- Aumento da confiabilidade do sistema

- Alteração de dados de processo (premissas adotadas durante o projeto)

- Implantação de novos projetos (Ex.: Implantação de equipamentos para redução de custos).

E seguindo esta linha, foi observado que na Companhia Siderúrgica do Atlântico tínhamos uma oportunidade de melhoria com relação à utilização de nitrogênio. Temos um nitrogênio menos nobre, por possuir uma concentração de até $2 \%$ a mais de oxigênio, que chamamos de nitrogênio waste, o qual temos um consumo abaixo do $7.000 \mathrm{Nm}^{3} / \mathrm{h}$ contratados. Em contrapartida temos um nitrogênio mais nobre, com maior pureza, que chamamos de nitrogênio LP (do inglês Low Pressure, em português Baixa Pressão). O contrato de nitrogênio waste prevê utilização média de $7.000 \mathrm{Nm}^{3} / \mathrm{h}$ e utilizávamos em média a metade do valor contratado, $3.500 \mathrm{Nm}^{3} / \mathrm{h}$. Já no contrato de nitrogênio LP, onde era previsto consumo médio de $12.000 \mathrm{Nm} 3 / \mathrm{h}$, havia um consumo médio bem acima do contratado, por volta de $21.600 \mathrm{Nm} 3 / \mathrm{h}$. Como podemos observar no Gráfico 1 abaixo, após reorganizarmos o histórico de dados de consumo de nitrogênio das maiores vazões para as mais baixas, a maior parte do tempo estamos consumindo abaixo dos $7.000 \mathrm{Nm}^{3} / \mathrm{h}$ contratados.

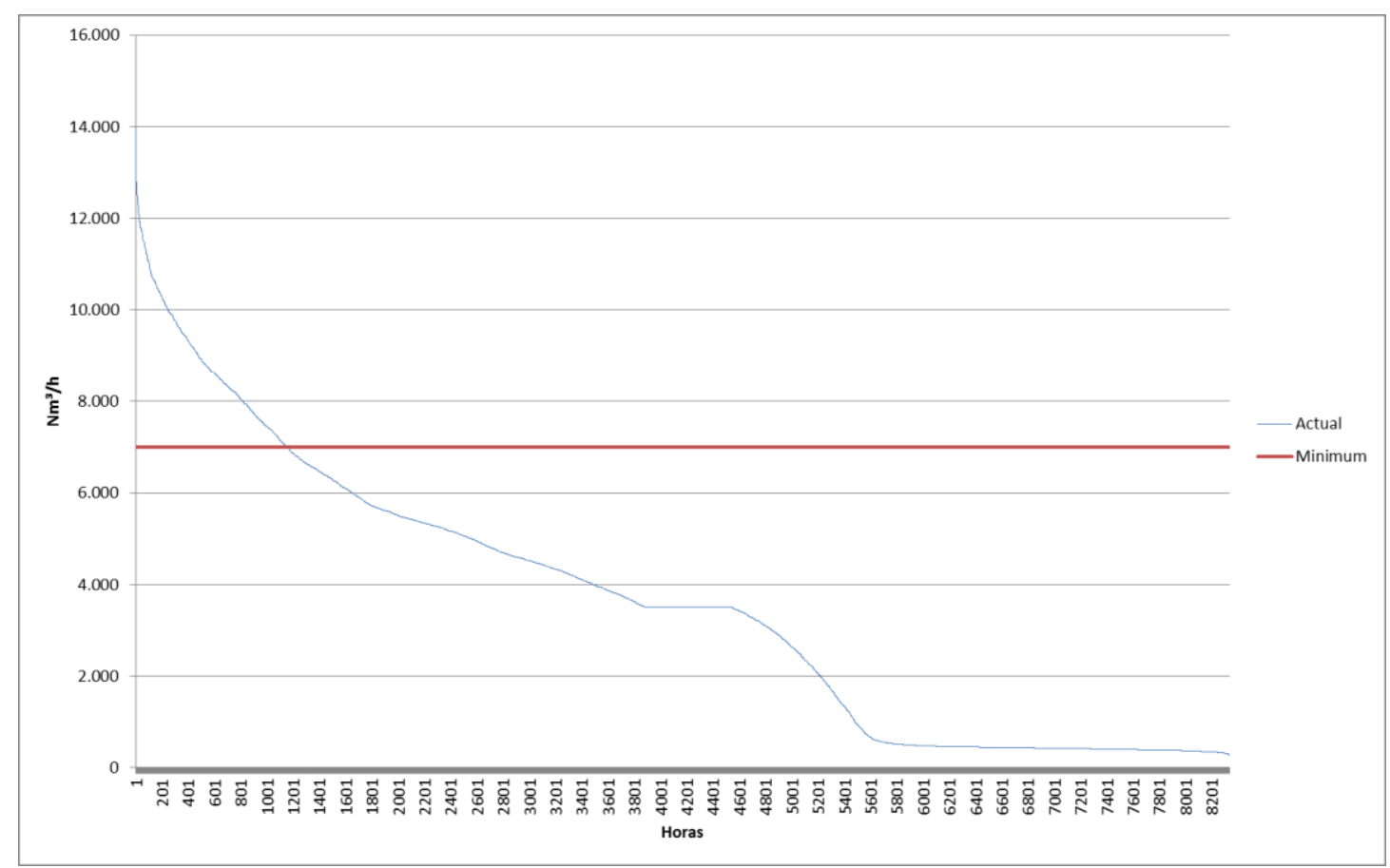

Gráfico 1 Consumo médio de Nitrogênio Waste na CSA 
Das áreas que necessitam do nitrogênio LP, algumas demandam de uma pureza maior (concentração máxima de oxigênio de 1\%),e uma de nossas preocupações é gerar instabilidade operacional nessas áreas, por isso, foi analisado a variação de concentração do oxigênio contido no nitrogênio waste durante todo o período contido no nosso banco de dados, e conforme podemos verificar no Gráfico 2, o nitrogênio waste atende a essa necessidade durante a maior parte do tempo.

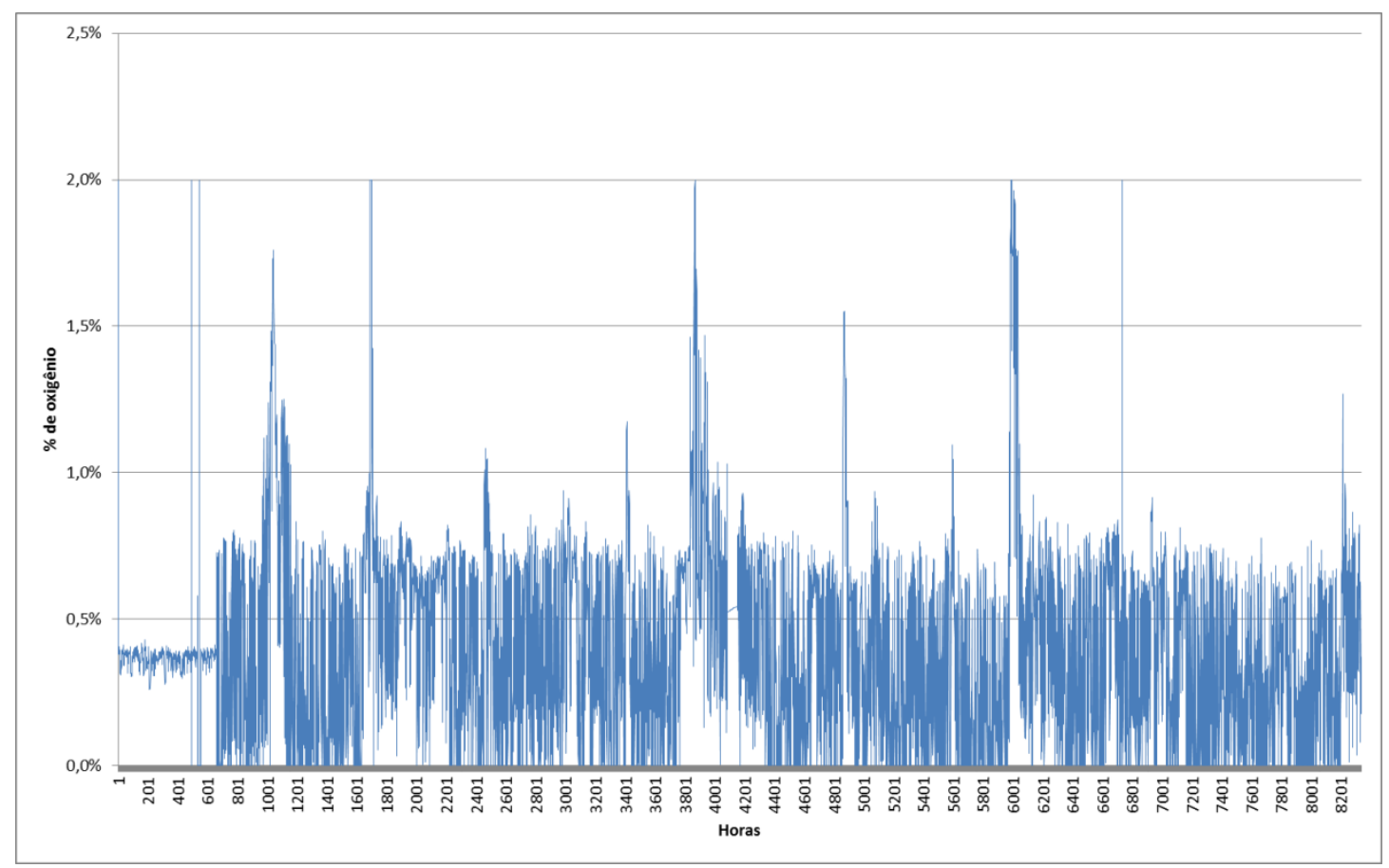

Gráfico 2 Concentração de Oxigênio no N2 Waste distribuído

Para facilitar a análise dos dados, foram reorganizadas as concentrações de oxigênio conforme estavam quando o nitrogênio waste foi distribuído no período referido, das concentrações maiores para as menores, conforme mostra o Gráfico 3:

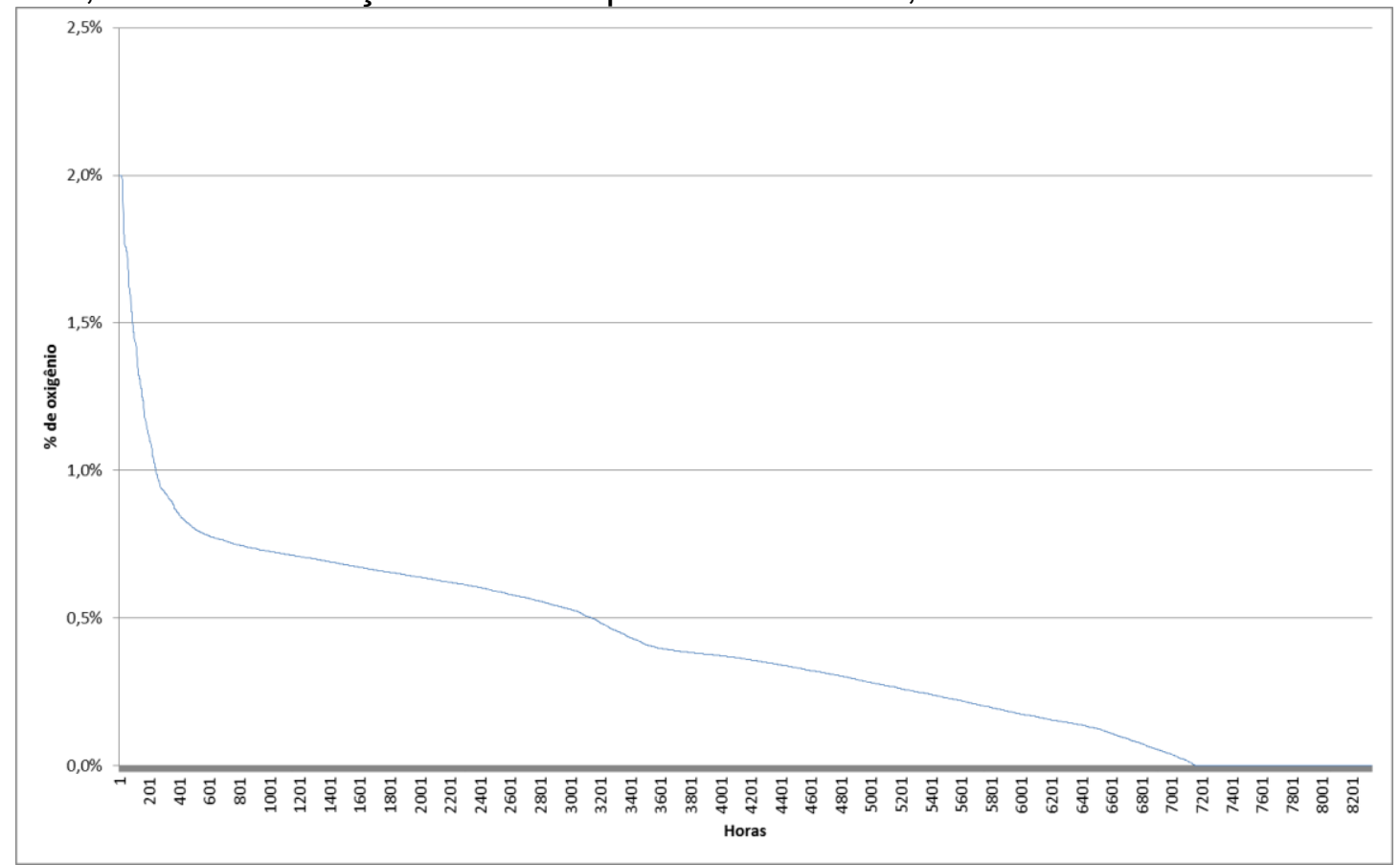

Gráfico 3 Concentração de Oxigênio no N2 Waste distribuído 
Analisando os dados acima, chegamos a conclusão que a maior parte do tempo temos uma concentração acima do $1 \%$ de oxigênio no nitrogênio waste, o que viabiliza tecnicamente a injeção do mesmo no nitrogênio de baixa pressão, ficando com a concentração de oxigênio abaixo do demandado pelas áreas mais restritivas. Após a análise da viabilidade de injeção de nitrogênio waste no nitrogênio de baixa pressão, o próximo passo foi realizar a avaliação da viabilidade econômica, e para facilitar o entendimento do cálculo, foi desenvolvido o esquema conforme mostrado na Figura 1. No lado esquerdo da Figura 1, o retângulo destacado com "1", representa a vazão média de nitrogênio waste que não é consumido (aproximadamente $3.500 \mathrm{Nm}^{3} / \mathrm{h}$ ), e no lado direito a possibilidade de economia, se o mesmo for injetado no nitrogênio de baixa pressão (Nitrogênio LP).

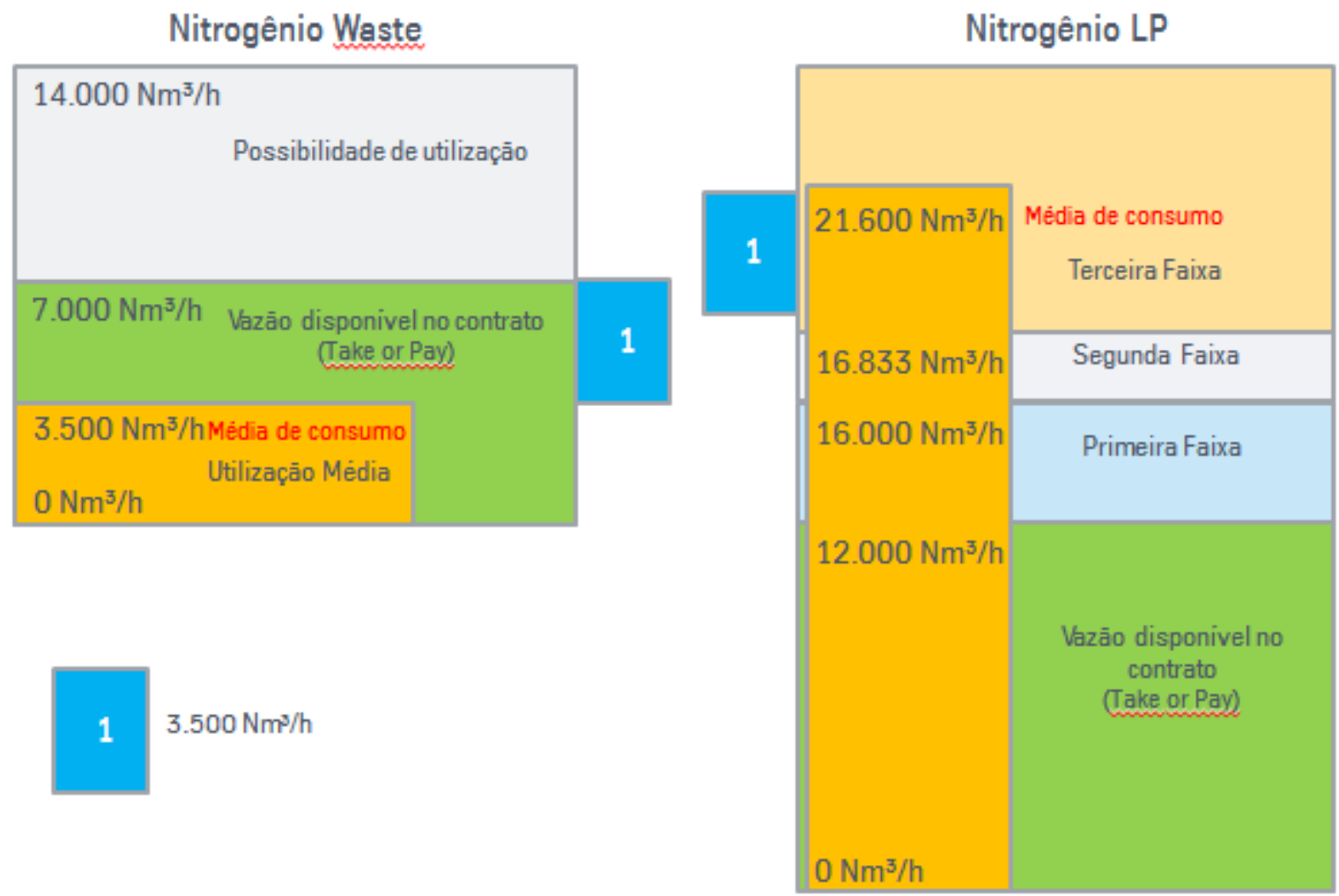

Figura 1 Uso Nitrogênio Waste x Nitrogênio LP

Para entendimento melhor, o nitrogênio de baixa pressão tem um take or pay de 12.000 Nm $3 / h$, os quais são pagos em um pacote mensalmente, sendo utilizados ou não. A partir do momento que ultrapassamos o take or pay, é cobrado um valor adicional, e os excedentes são divididos em três faixas:

- De $12.001 \mathrm{Nm}^{3} / \mathrm{h}$ à $16.000 \mathrm{Nm}^{3} / \mathrm{h}$, é pago o valor da primeira faixa;

- De $16.001 \mathrm{Nm}^{3} / \mathrm{h}$ à $16.833 \mathrm{Nm}^{3} / \mathrm{h}$, é pago o valor da segunda faixa (valor maior que o valor da primeira faixa);

- Consumo acima de $16.834 \mathrm{Nm}^{3} / \mathrm{h}$ é pago o valor da terceira faixa (e um valor maior que o valor da segunda faixa).

\section{MATERIAIS E MÉTODOS}

Após as análises de dados concluídas, partimos para a elaboração física do projeto, desenvolvendo a tubulação de interligação das redes já mencionadas. 


\subsection{Definição de Parâmetros para o projeto da tubulação}

Como premissa de projeto, foi adotada uma vazão de $4.000 \mathrm{Nm}^{3} / \mathrm{h}$, devido a vazão média de $3.500 \mathrm{Nm}^{3} / \mathrm{h}$ que não é utilizada, ou seja, algumas horas a vazão está acima da vazão média, e outras horas estão abaixo.

Após cálculos realizados, chegamos ao resultado que o diâmetro de 4" é o suficiente para atender às necessidades do projeto.

Partimos então para a especificação de materiais de acordo com a PIPING LINE SPECIFICATION. Para definir os materiais da confecção da tubulação, utilizamos as propriedades do fluído para na Tabela 1 para buscar a localização da especificação da tubulação na Pipe line specification, no caso "C8", conforme destacado em amarelo:

6. Pipe line Specifications Table for Bop Media

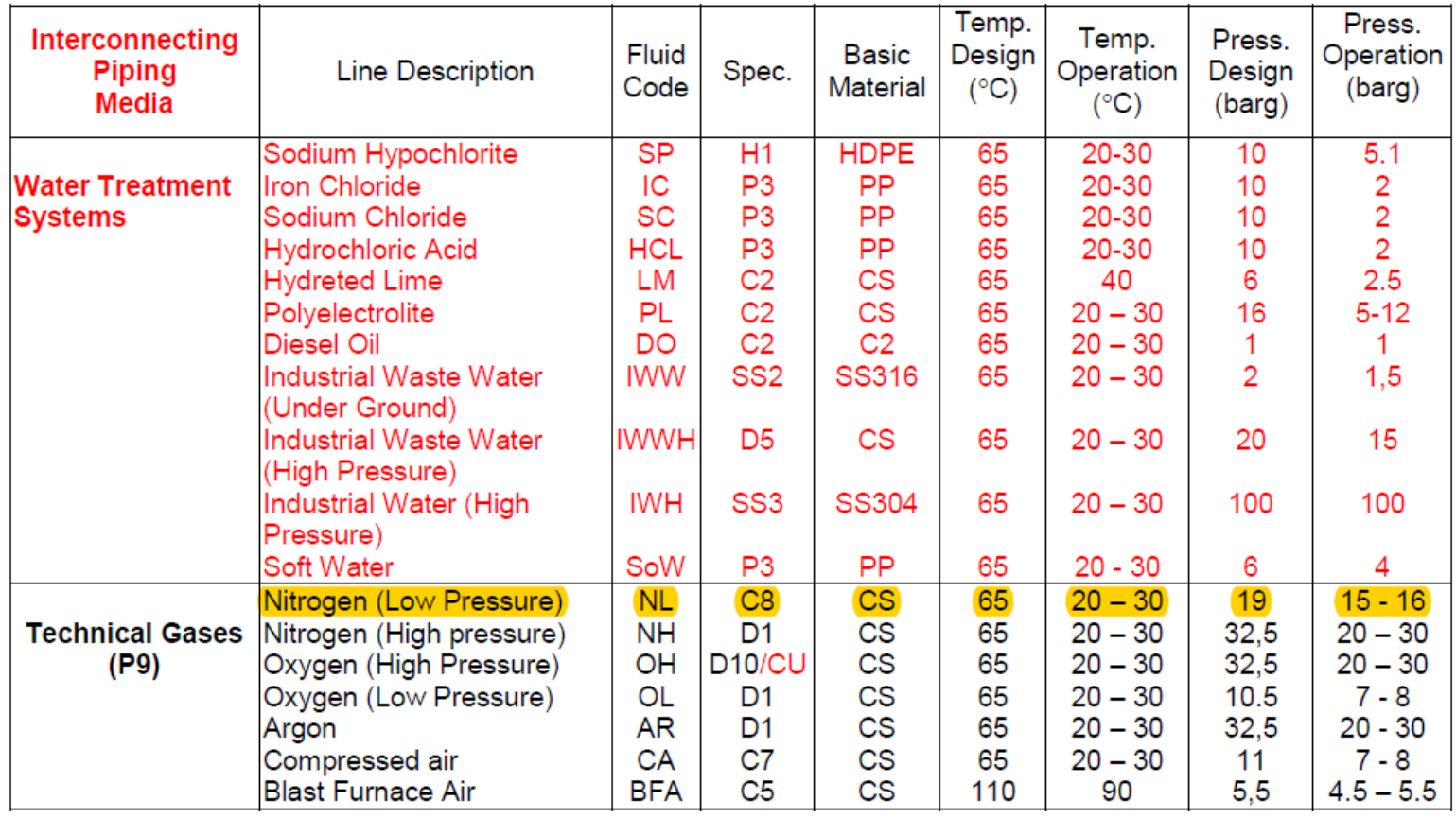

Tabela 1 Propriedades do fluído

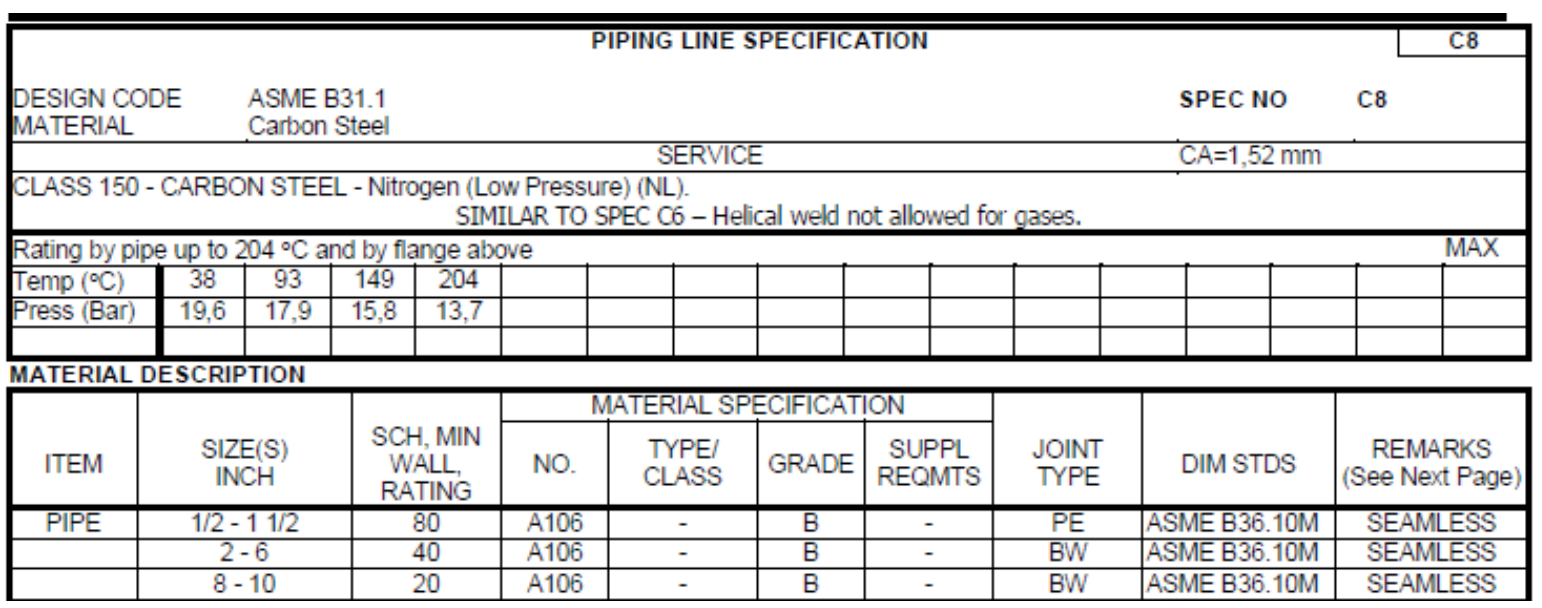

Tabela 2 Definição de material da tubulação para projeto 
Indo na especificação "C8", conforme mostra Tabela 2, obtemos as especificações necessárias para a tubulação (schedule, tipo de material, tipo de junta, entre outros).

\subsection{Montagem da tubulação de interligação}

Durante a montagem de aproximadamente 420 metros da tubulação, foram seguidos procedimentos já implantados de montagem e serviços a quente, como:

- Serviços de solda;

- Serviços com maçarico;

- Serviços com máquinas motrizes (lixadeira / esmerilhadeiras);

- Trepanação.

Um destaque para o procedimento de trepanação, também chamado de furo em carga, que foi realizado em três pontos, garantindo o fornecimento de nitrogênio sem interrupções, ou seja, com fluxo contínuo do fluído na pressão de trabalho do mesmo, durante $o$ andamento da montagem.

Toda a tubulação foi preparada no solo (feito biselamento e acabamentos), após isso posicionada abaixo do pipe rack onde a mesma seria montada. Com o auxilio de guindaste a mesma foi posicionada no pipe rack, em locais já pré-definidos e foram montados andaimes para realizar a solda. Após solda das tubulações, foram executados todos os ensaios de qualidade (que serão mencionados no próximo item do trabalho) que foram aprovados, e com isso foi realizado a pintura da tubulação no padrão CSA.

\subsection{Ensaios realizados após montagem}

Conforme indicado na norma NBR 15358/2013 - Rede de distribuição interna para gás combustível em instalações de uso não residencial, foram realizados os ensaios abaixo, a fim de garantir a integridade da montagem da tubulação de interligação e da rede de distribuição de nitrogênio da planta:

- Teste hidrostático (uma vez e meia a pressão de trabalho da linha);

- Secagem da linha com PIG.

- A purga com gás inerte não foi necessário, pois o nitrogênio já é cum gás inerte.

Além dos testes recomendados pela NBR 15358/2013, foram também executados os testes abaixo:

- Inspeção com liquido penetrante em todas as soldas;

- Inspeção dimensional;

- Teste hidrostático (uma vez e meia a pressão de trabalho da linha);

- Lavagem da linha de interligação (flush);

- Realizar ensaio de ultrassom em 30\% da tubulação.

\subsection{Elaboração de lógica de controle de injeção de nitrogênio waste no nitrogênio de baixa pressão}

Foi instalado uma rack de controle na rede de interligação, onde o mesmo é feito através das variantes pressão, temperatura, vazão e porcentagem de oxigênio no Nitrogênio. Foi elaborada uma lógica para garantir a concentração mínima de oxigênio não ultrapasse o exigido pelas áreas produtivas (Alto forno e Termelétrica por exemplo), e que a pressão do Buffer de Nitrogênio Waste seja suficiente para garantir o processo de "Slag Splash" na Aciaria. 


\section{RESULTADOS E DISCUSSÃO}

No início do projeto a maior preocupação era de a injeção provocar instabilidades nos diversos processos produtivos da planta, mas nos testes e após os primeiros meses de operação da injeção, tivemos ótimos resultados, desde não provocar nenhuma perda de rendimento e qualidade nos processos produtivos até a estabilização de alguns parâmetros como por exemplo a estabilização da tensão de inertização do precipitador da termelétrica (conforme mostrado na Figura 2, os intervalos que há estabilização é o momento que o nitrogênio waste está sendo injetado), além de conseguir atingir uma injeção média acima de $3.900 \mathrm{Nm} 3 / \mathrm{h}$.

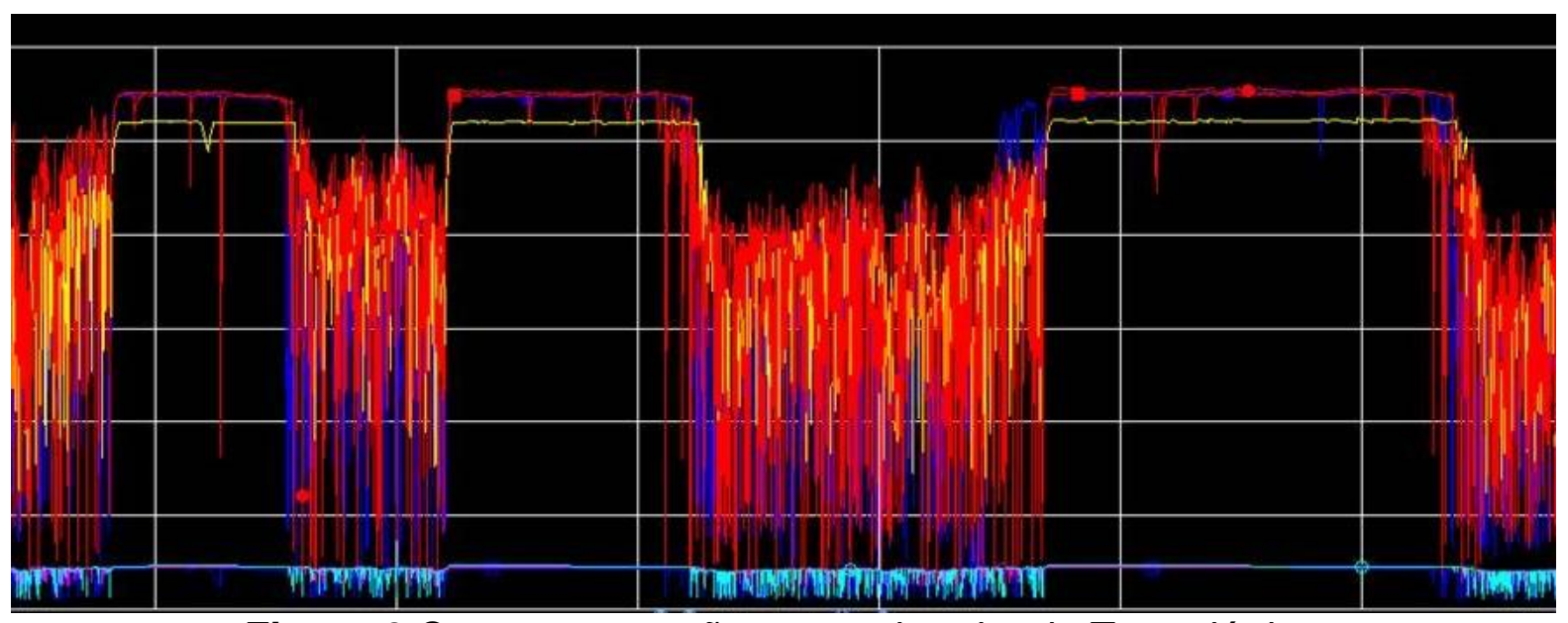

Figura 2 Corrente e tensão no preciptador da Termelétrica

Durante os testes e após o início da operação do sistema de injeção, foram realizados testes de melhoria, onde foram feitas revisões dos valores de set-up definidos em projeto, buscando uma maior economia com a injeção de nitrogênio waste no nitrogênio de baixa pressão.

Como podemos averiguar no Gráfico 4, os valores obtidos com a economia na injeção, foram superiores aos valores planejados:

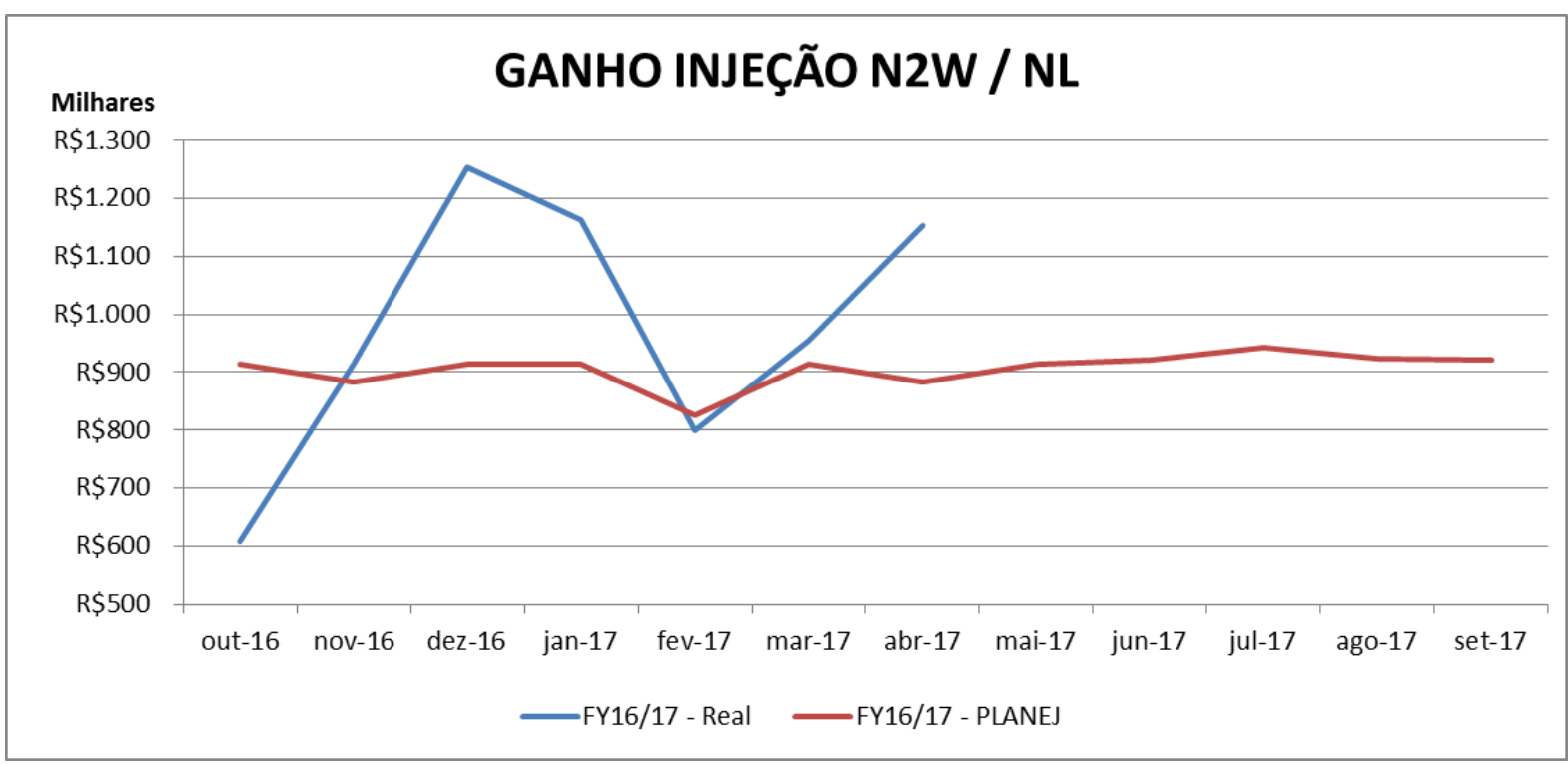

Gráfico 4 Ganho Planejado x Real Injeção Nitrogênio Waste 


\section{CONCLUSÃO}

Esse trabalho nos mostrou que devemos estar sempre atentos aos resultados de nossos processos, pois com o projeto de interligação de dois fluídos diferentes, após a avaliação de todos os impactos possíveis nas áreas produtivas, elaboração de um sistema de intertravamento garantindo a segurança do sistema e dos processos, foi possível produzir um mix de nitrogênio, sem descaracterizar as propriedades fisioquímicas do gás gerando uma economia média de aproximadamente 01 milhão de reais por mês.

Um fato a se destacar também é que o projeto se pagou com menos de 2 meses de implantação.

\section{REFERÊNCIAS}

$1 \quad$ Drasdo Frank, Piping Line Specification BOP Media CSA, 2008. 